\title{
A short-term approach for promoting oral health of internally displaced children with PTSD: the key is improving mental health—results from a quasi-randomized trial
}

\author{
Sulaf Hamid ${ }^{1 *}$ D, Mayssoon Dashash ${ }^{1,2}$ and Youssef Latifeh ${ }^{3,4}$
}

\begin{abstract}
Background: Several studies have demonstrated that mental $(\mathrm{MH})$ and oral health $(\mathrm{OH})$ of displaced children are negatively affected during the wartime. This may be a result of general self-neglect and psychological suffering. Therefore, previous studies suggested that psychosocial support (PSS) is essential during and after humanitarian crises to prevent immediate and long-term $\mathrm{MH}$ and $\mathrm{OH}$ problems. This study was undertaken to evaluate the effectiveness of a short-term approach in improving $(\mathrm{MH})$ and $(\mathrm{OH})$ of displaced children suffering from posttraumatic stress disorder (PTSD).

Methods: A quasi-randomized clinical trial study was carried out including (118) displaced children suffering from PTSD. The Child Post-Traumatic Stress Reaction Index (CPTSD-RI) was utilized for the diagnosis of PTSD. Children were assigned into two groups (intervention and control group). Children in the intervention group were enrolled in a 6-week PSS program that contained oral health educational components designed especially for this study. Clinical evaluation included plaque index (PI) and gingival index (Gl). Oral health related Quality of life (OHRQoL) was also evaluated using child perception questionnaire $\left(\mathrm{CPQ}_{11-14}\right)$. Study variables were evaluated at baseline and at the end of the program for both groups. Wilcoxon rank test and $t$-test for independent samples were used for data analysis.

Results: A total of 118 children, aged between 9 and 14 years, participated in the recent study (mean age $11.0 \pm 1.4)$. All participated children were previously diagnosed with PTSD. At baseline, there were no significant differences in the study variables between groups $(P>0.05)$. At the end of the program, children in the intervention group had significantly decreased PI, $\mathrm{Gl}, \mathrm{CPQ}_{11-14}$ and $\mathrm{CPTSD}-\mathrm{Rl}$ compared to their baseline scores $(P=0.000)$. In contrast, controls showed no differences at the end of the program $(P>0.05)$. Children in the intervention group had significantly $(P=0.000)$ lower PI $(1.52 \pm 0.55)$ and $\mathrm{Gl}(1.48 \pm 0.56)$ when compared to controls $(\mathrm{PI}=1.89 \pm 0.39$, $\mathrm{Gl}=2.14 \pm 0.32)$ post program. Moreover, the intervention group showed remarkable decline $(P<0.001)$ in their $\mathrm{CPQ}_{11-14}(47.16 \pm 12.24)$ and $\mathrm{CPTSD}-\mathrm{RI}(34.41 \pm 12.23)$ scores compared to controls $\left(\mathrm{CPQ}_{11-14}=72.65 \pm 14.47\right.$, CPTSD$\mathrm{Rl}=47.91 \pm 14.24)$ post program.
\end{abstract}

\footnotetext{
*Correspondence: sulaf-rose@hotmail.com

${ }^{1}$ Department of Pediatric Dentistry, Faculty of Dentistry, Damascus

University, Damascus, Syria

Full list of author information is available at the end of the article
} original author(s) and the source, provide a link to the Creative Commons licence, and indicate if changes were made. The images or other third party material in this article are included in the article's Creative Commons licence, unless indicated otherwise in a credit line to the material. If material is not included in the article's Creative Commons licence and your intended use is not permitted by statutory regulation or exceeds the permitted use, you will need to obtain permission directly from the copyright holder. To view a copy of this licence, visit http://creativecommons.org/licenses/by/4.0/. The Creative Commons Public Domain Dedication waiver (http://creativeco mmons.org/publicdomain/zero/1.0/) applies to the data made available in this article, unless otherwise stated in a credit line to the data. 
Conclusions: The designed approach could have positive improvements in PTSD symptoms, $(\mathrm{OH})$ and (OHRQoL) of displaced children. Integration between $(\mathrm{MH})$ and $(\mathrm{OH})$ services should be considered during and after humanitarian crises to prevent immediate and long-term $\mathrm{MH}$ and $\mathrm{OH}$ problems.

Trial registration Australian New Zealand Clinical Trials Registry (ACTRN12619000285156), Date registered: 25/02/2019, retrospectively registered. https://anzctr.org.au/Trial/Registration/TrialReview.aspx?id=377001\&isReview=true.

Keywords: Approach, Promoting oral health, PTSD, Children

\section{Background}

Most of children exposed to ongoing stressors of war will experience significant psychological morbidity [1]. Moreover, displacement as a usual consequence of war, also force children and their families to live in unhealthy conditions of malnutrition, overcrowding and psychological uncertainty [2]. This is the case now for Syrian Families. While the war is about to terminate, still the post-war period seems to be even harder for Syrians. MH now is a major problem since outpatients have been dramatically increased in psychiatric clinic during the crisis [3]. Furthermore, $\mathrm{OH}$ is negatively affected. A recent study showed that gingivitis prevalence reached $97.93 \%$ among children during the crisis [4]. Unfortunately, $\mathrm{OH}$ has less attention by researchers and health policy makers during a wartime compared to $\mathrm{MH}$. Still, $\mathrm{OH}$ can add fuel to fire for mentally ill people if they happen to encounter. A study found that oral symptoms may be the first or the only manifestation of (MH) problem that may affect QoL [5]. In another hand, previous studies have demonstrated that people with $(\mathrm{MH})$ problems are prone to develop $(\mathrm{OH})$ problems because of the general selfneglect resulting from their psychological suffering $[6$, 7]. Recently, WHO referred to $\mathrm{MH}$ as an integral part of public health programs and not a specialist activity setting apart [8]. In addition to the fact that integration between $(\mathrm{MH})$ and non-specialized healthcare is a possible strategy to make targeted interventions sustainable [9]. The aim of the current study was to evaluate the effectiveness of short-term approach in improving $(\mathrm{MH})$ and $(\mathrm{OH})$ of displaced children suffering from posttraumatic stress disorder (PTSD).

\section{Methods}

\section{Ethical considerations}

This study was approved by the Ethical Committee of the Faculty of Dentistry in Damascus University, Syria. All children participated in the current study were informed, along with their parents, about the study aims and procedures. Parents/guardians have signed the written informed consent.

\section{Study design and sample}

This study has a quasi-randomized controlled trial design. The study carried out in 2017, Damascus, Syria. During this year Damascus city had 8 temporary accommodation centers (TACs). These centers were set up by the government to receive displaced families coming from hot areas (around Damascus and different parts of Syria). Four TACs were selected from four different areas in Damascus city. All children aged between 9 and 14 years living in TACs were invited to participate.

\section{Study procedures Randomization and sampling}

Two TACs (out of four) were selected to apply the intervention (intervention group). The other two centers served as control group. Randomization for selecting TACs was utilized by means of coin toss. Inclusion and exclusion criteria are shown in Fig. 1. (The flow chart of children participated in this study). Clinical examination and questionnaires were evaluated at baseline and within one week at the end of the program (after the 6-week approach).

A total of 40 patients in each group were necessary to reach $80 \%$ of statistical power according to a previous similar study [10]. Therefore, a total sample size should include eighty subjects $(\mathrm{N}=80)$. To allow adjustment of other factors such as withdrawals and missing data, additional subjects ( 20 subjects) were added to each group. Therefore, the study included an intervention group $(n=60)$ and a matching controls $(n=60)$.

\section{Diagnosis of PTSD}

Only children with PTSD participated in the recent study. PTSD was assessed prior to the intervention using CPTSD-RI. This self-report questionnaire had 20 items assessing PTSD symptoms among children aged between 6 and 16 years [11]. Previous studies showed that the Arabic version of this scale is reliable and valid [12]. High scores indicate worse symptoms.

\section{OHRQoL assessment}

OHRQoL was assessed using the $\mathrm{CPQ}_{11-14}$ self-report scale [13]. This scale has 36 questions about how oral 


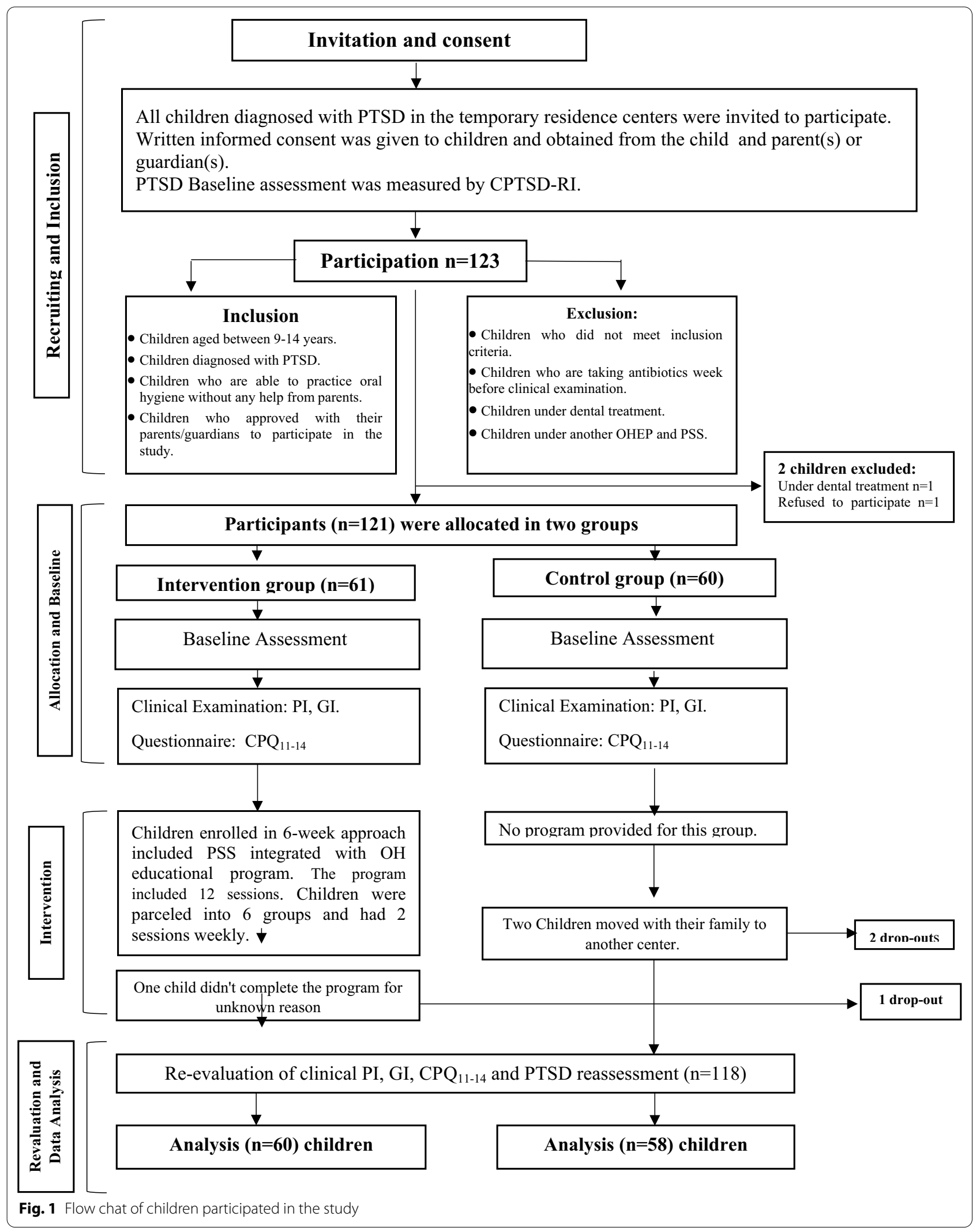


symptoms, Functional limitation, emotional and social wellbeing are affected by $\mathrm{OH}$. The Arabic version of the scale showed high reliability and validation [14].

Children were asked to complete the two questionnaires pre and post program. Each questionnaire took about 15-20 min to complete. Children were instructed to read and answer the questionnaire themselves. They were also informed about the possibility of withdrawing from the study at any point. A pediatric dentist (SH) and a psychologist (YL) was supervising this process and were available at any time to answer any question.

\section{Clinical examination}

The same investigator $(\mathrm{SH})$ held out the clinical examination of children in both groups. $\mathrm{OH}$ was evaluated using PI [15] and GI [16]. The indices were recorded for all children pre and post program. The clinical examination performed according to the basic methods and diagnostic criteria of WHO [17].

\section{Description of the approach}

A short-term approach was designed specifically for this study. The 12-session program was carried out for 6 weeks. The program included 8 sessions of PSS and 4 sessions of educational materials about $\mathrm{OH}$. The same pediatric dentist $(\mathrm{SH})$ held the OHEP, while two welltrained social workers conducted PSS part of the program. The same psychologist (YL) supervised the whole sessions and was always available in case any children had serious symptoms and needed urgent referral. Children attended two sessions weekly in terms of sub-groups. The intervention group included 6 sub-groups. Each subgroup consisted of 18-20 children. For six weeks, the exact same session was conducted for two sub-groups in the first three days of the week. In the following three days, a new session was carried out. Every session took about 60-90 min. Sessions had various integrated activities such as playing, drawing, acting and relaxation methods. Educational materials about $\mathrm{OH}$ included presentations, videos, illustration tools and storytelling. PSS focused on trauma healing, open discussions about social problems, friendly behavior and positive vision about the future. The educational program focused on oral diseases and their consequences on General Health. It also focused on prevention methods, treatment procedures/ tools, stages of teething and dental appearance. Children were also educated about the importance of $\mathrm{OH}$ to the whole body and how periodic checkups are necessary for their $\mathrm{OH}$.

Children in the control group served as a comparison group to assess the spontaneous improvement -if anyof study variables without any intervention. It would be unethical to include only children in the intervention group participated in the designed approach. Therefore, children in the control group were also invited to experience the same exact program at the end of the study.

\section{Statistical analysis}

Data were analyzed by means of SPSS program (SPSS 20, SPSS Inc. Chicago, IL, USA). Kruskall-Wallis test was used to check the normality distribution of the data. Data of the recent study weren't normally distributed. Therefore, Wilcoxon signed rank test was used to assess the mean changes over time pre/post program in the same group. Independent sample $t$-test was used to measure differences between the intervention and the control group pre/post program. The $P$ value for all tests was set at 0.05 .

\section{Results}

A total of 118 children aged 9-14 years (mean age was $11.0 \pm 1.4$ years) participated in this study. The intervention group $(n=60)$ included $38.3 \%$ boys and $61.7 \%$ girls. The controls $(n=58)$ included $34.5 \%$ boys and $65.5 \%$ girls. Table 1 presents the distribution of participated children according to demographic characteristics and group.

Table 2 presents the PI, GI, CPQ $11-14$ and CPTSD-RI for children in intervention and control group pre and post program. Findings revealed no significant differences $(P>0.05)$ between the intervention and the control groups regarding baseline scores for all study variables. Post program children in the intervention group showed significantly $(P=0.000)$ lower scores regarding PI

Table 1 Demographics of PTSD children in both intervention and control groups

\begin{tabular}{|c|c|c|c|c|c|c|c|}
\hline \multirow{2}{*}{$\frac{\text { Groups }}{\text { Variables }}$} & & \multicolumn{2}{|c|}{ Intervention } & \multicolumn{2}{|c|}{ Control } & \multicolumn{2}{|c|}{ Total } \\
\hline & & $\mathrm{n}$ & $\%$ & $\mathrm{n}$ & $\%$ & $\mathbf{N}$ & $\%$ \\
\hline \multirow[t]{2}{*}{ Gender } & Boy & 23 & 38.3 & 20 & 34.5 & 43 & 36.4 \\
\hline & Girl & 37 & 61.7 & 38 & 65.5 & 75 & 63.6 \\
\hline \multicolumn{2}{|l|}{ Total } & 60 & 100 & 58 & 100 & 118 & 100 \\
\hline Age & mean $\pm S D$ & \multicolumn{2}{|c|}{$10.9 \pm 1.4$} & \multicolumn{2}{|c|}{$11.1 \pm 1.4$} & \multicolumn{2}{|c|}{$11.0 \pm 1.4$} \\
\hline
\end{tabular}

SD, Standard Deviation 
Table 2 Differences between PTSD children in intervention and control group according to oral (PI, GI) and mental (CPQ $\left.{ }_{11-14}, \mathrm{CPTSD}-\mathrm{RI}\right)$ health variables pre and post program

\begin{tabular}{|c|c|c|c|c|c|c|c|c|}
\hline \multirow[t]{2}{*}{ Variable } & & \multicolumn{3}{|c|}{ Intervention } & \multicolumn{3}{|c|}{ Control } & \multirow[t]{2}{*}{ Differences** } \\
\hline & & mean & SD & $P$ value* & mean & SD & $P$ value* & \\
\hline \multirow[t]{2}{*}{ PI } & Pre & 2.15 & 0.64 & 0.000 & 1.97 & 0.53 & 0.035 & 0.114 \\
\hline & Post & 1.52 & 0.55 & & 1.89 & 0.39 & & $0.000^{* *}$ \\
\hline \multirow[t]{2}{*}{ Gl } & Pre & 2.13 & 0.45 & 0.000 & 2.14 & 0.50 & 0.873 & 0.927 \\
\hline & Post & 1.48 & 0.56 & & 2.14 & 0.32 & & $0.000^{* *}$ \\
\hline \multirow[t]{2}{*}{$C P Q_{11-14}$} & Pre & 74.80 & 15.97 & 0.000 & 75.29 & 12.30 & 0.175 & 0.852 \\
\hline & Post & 47.16 & 12.24 & & 72.65 & 14.47 & & $0.000^{* *}$ \\
\hline \multirow[t]{2}{*}{ CPTSD-RI } & Pre & 45.66 & 14.86 & 0.000 & 45.81 & 13.94 & 0.075 & 0.957 \\
\hline & Post & 34.41 & 12.23 & & 47.91 & 14.24 & & $0.000^{* *}$ \\
\hline
\end{tabular}

PI, Plaque Index; Gl, Gingival Index; $\mathrm{CPQ}_{11-14}$, Child Perception Questionnaire age between 11 and14; CPTSD-RI, Child Posttraumatic Stress Reaction Index; SD, Standard Deviation

*Wilcoxon Signed Ranks Test

**Independent samples t-test

$(1.52 \pm 0.55)$ and GI $(1.48 \pm 0.56)$ compared to the controls $(\mathrm{PI}=1.89 \pm 0.39, \mathrm{GI}=2.14 \pm 0.32)$. Their $\mathrm{CPQ}_{11-14}$ score was also significantly lower $(47.16 \pm 12.24)$ compared to the controls $(72.65 \pm 14.47)$. Moreover, the CPTSD-RI have been significantly $(P=0.000)$ decreased post program in the intervention group $(34.41 \pm 12.23)$ compared to controls $(47.91 \pm 14.24)$.

Table 3 presents the differences between boys and girls in intervention group according to all health variables pre and post program. Baseline scores showed that boys and girls had similar scores with no significant differences regarding study variables $(P>0.05)$. Post program, both boys and girls in the intervention group revealed significant $(P<0.05)$ decline in all study variables. However, girls had significantly lower PI $(1.34 \pm 0.57)$ compared to boys $(1.81 \pm 0.39)$ post program. Moreover, girls also showed significantly $(P=0.023)$ lower CPTSD-RI score $(31.62 \pm 12.23)$ compared to boys $(38.91 \pm 11.04)$ post program.

\section{Discussion}

The aim of psychosocial interventions inside wider developmental contexts such as healthcare is to create an integrated developmental approach to promoting psychosocial wellbeing. Integrative approaches of education on health and psychosocial support must be accompanied by more efforts. In this way, the psychosocial wellbeing of children can be assured [18]. Therefore, the aim of the current study was to evaluate the effectiveness of a novel approach in improving both $\mathrm{MH}$ and $\mathrm{OH}$ of

Table 3 Differences between boys and girls in intervention group according to oral (PI, GI) and mental $\left(\mathrm{CPQ}_{11-14}\right.$ CPTSD-RI) health variables pre and post program

\begin{tabular}{|c|c|c|c|c|c|c|c|c|}
\hline \multirow[t]{2}{*}{ Variable } & & \multicolumn{3}{|l|}{ Boys } & \multicolumn{3}{|l|}{ Girls } & \multirow[t]{2}{*}{ Differences** } \\
\hline & & mean & SD & $P$ value* & mean & SD & $P$ value* & \\
\hline \multirow[t]{2}{*}{ PI } & Pre & 2.28 & 0.45 & 0.000 & 2.06 & 0.73 & 0.000 & 0.217 \\
\hline & Post & 1.81 & 0.39 & & 1.34 & 0.57 & & $0.000^{* *}$ \\
\hline \multirow[t]{2}{*}{ Gl } & Pre & 2.05 & 0.43 & 0.000 & 2.18 & 0.45 & 0.000 & 0.296 \\
\hline & Post & 1.53 & 0.55 & & 1.45 & 0.56 & & 0.602 \\
\hline \multirow[t]{2}{*}{$C P Q_{11-14}$} & Pre & 73.82 & 16.67 & 0.000 & 75.40 & 15.71 & 0.000 & 0.716 \\
\hline & Post & 48.69 & 12.38 & & 46.21 & 12.22 & & 0.452 \\
\hline \multirow[t]{2}{*}{ CPTSD-RI } & Pre & 45.56 & 13.12 & 0.001 & 45.72 & 16.03 & 0.000 & 0.967 \\
\hline & Post & 38.91 & 11.04 & & 31.62 & 12.23 & & $0.023^{* *}$ \\
\hline
\end{tabular}

PI, Plaque Index; Gl, Gingival Index; $\mathrm{CPQ}_{11-14}$, Child Perception Questionnaire age between 11 and 14; CPTSD-RI, Child Posttraumatic Stress Reaction Index; SD, Standard Deviation

*Wilcoxon Signed Ranks Test

**Independent samples t-test 
children traumatized by war. For this purpose, children suffered from PTSD were enrolled into a short-term approach designed especially for this study. The Designed approach provided PSS integrated with OHEP.

The recent study had a quasi-randomized trial for financial and practical constrains related to the war circumstances. Children were randomly selected from four temporary accommodations centers. Children related to two centers, were allocated to intervention group whilst children related to other two centers were allocated to control group. By separating the intervention and the control groups, the contamination between study participants was controlled.

The used approach had positive effects on children suffering from PTSD after participating in the study program. Children enrolled in the program showed significant improvement in their PTSD symptoms. They had better $\mathrm{OH}$ status and OHRQoL post program compared to baseline scores. On the other hand, children in the control group showed no or slight improvement and sometimes worse scores post-program. This can be explained by the fact that those children were still under the stressor and distress of war without any kind of PSS.

In this study, the short-term approach was provided to traumatized Syrian children affected by the war. Most previous studies on war children focused more on treatment techniques utilized by psychologists rather than PSS provided by non-specialists [18]. Unfortunately, MH service in Syria have not yet been integrated into public health care strategies. Therefore, governmental and nongovernmental associations have trained social worker personnel to provide PSS to affected and displaced children. Nonetheless, no previous studies have reported the effectiveness of such services.

A significant reduction in PTSD symptoms among intervention group was reported. Dybdahl found Similar findings in 2001. He concluded that group-PSS had significantly improved $\mathrm{MH}$ of internally displaced children post war. The program integrated with basic medical care. The study also involved mothers of the children [19]. In the contrary, another study did not find significant impact of group intervention provided to Palestinian children suffering from PTSD. The authors attributed this to the continuing exposure to trauma and non-active nature of the intervention [10].

It is worth mentioning that the recent study focused more on PSS part of the approach rather than on the OHE. Integrated OHE was a way to change the traditional method of providing PSS into enjoyable and useful process rather than focusing on trauma itself. The plaque and gingival indices were used to evaluate changes in the $\mathrm{OH}$ status. Future longitudinal studies that consider other $\mathrm{OH}$ evaluations could be used to investigate changes over time. In the recent study, both PI and GI have significantly declined among children in the intervention group post program. A recent study (2018) conducted on 220 schoolchildren aged between 10 and 11 years in Syria showed that Plaque and Gingival Indices were improved after 6 weeks of educational program on $\mathrm{OH}$ compared to baseline [20]. However, the study did not study the psychological well-being of the children and did not provide a PSS.

Girls in the recent study showed lower PI compared to boys pre and post program. They also showed significant improvement in PTSD symptoms compared to boys post program. A previous study found similar results after school-based $\mathrm{MH}$ intervention carried out in conflictaffected areas in Indonesia [21].

\section{Study limitations}

Previous studies have focused only on general health when providing PSS integrated with healthcare. This novel approach was the first of its kind in the medical literature trying to add outcomes regarding $\mathrm{OH}$ promotion through PSS during humanitarian emergences. Still, this study has some limitations. One of the limitations was that PTSD diagnosis relied only on the self-report questionnaire and not on structured interview with a psychologist. Another limitation was that the same investigator conducted the clinical examination post program, which may influenced the objectivity of the assessment. Moreover, the TACs in Damascus city were all closed after a short time of our study. Most of the participated children had left the TACs to their original residence as a part of the "coming back home" plan established by the government post war. Therefore, tracing the long-term effects of our short-term approach was not available.

\section{Conclusions}

The improvement of both oral and mental health of displaced children was observed after a short-term approach focused in PSS and OHE. The designed approach had positive improvements in PTSD symptoms, $(\mathrm{OH})$ ) and $(\mathrm{MH})$ of displaced children. This proves that integration between $\mathrm{MH}$ and $\mathrm{OH}$ services can be suggested during and after humanitarian crises to prevent immediate or long-term $\mathrm{MH}$ and $\mathrm{OH}$ problems. We believe that, dentists, as health care professionals, have an obligation to play a role in health care strategies and interventions such as PSS. Therefore, these kinds of interventions may improve overall health outcomes and lead to a healthier society.

\section{Abbreviations}

PTSD: Posttraumatic stress disorder; CPTSD-RI: Child posttraumatic stress reaction index; PSS: Psychosocial support; OHEP: Oral health educational program; 
OH: Oral health; MH: Mental health; OHRQoL: Oral health related Quality of life; PI: Plaque index; Gl: Gingival index; $\mathrm{CPQ}_{11-14}$ : Child perception questionnaire from 11 to 14 years; TACs: Temporary accommodation centers; SD: Standard Deviation; SH: Sulaf Hamid; MD: Mayssoon Dashash; YL:: Youssef Latifeh.

\section{Acknowledgement}

The authors would like to thank all the children participated in this study as well as the social workers.

\section{Authors' contributions}

SH carried out the data collection, data analysis and drafted the manuscript. MD supervised the study, participated in its design and revised the paper to its final version. YL supervised the study, Trained the social workers and revised the paper to its final version. All authors approved and are responsible of the final manuscript. Damascus University approved the design of the study. It also funded the data collection part of the study by providing the necessary tools and equipment. "All authors read and approved the final manuscript.

\section{Funding}

This research was funded by Damascus University. The University funded all the equipment and aids used in the program. It also funded the clinical examination tools and printing of the questionnaires.

\section{Availability of data and materials}

The datasets used and/or analyzed during the current study are available from the corresponding author on reasonable request.

\section{Ethics approval and consent to participate}

The study was approved by the Ethical Committee of the Institutional Review Board of the Faculty of Dentistry in Damascus University, Syria in may-16-2016 (Ethics approval \#2039). Children were given a written consent form. Only children with signed consents from parent(s) or guardian(s) were enrolled in this study.

\section{Consent for publication}

Not applicable.

\section{Competing interests}

The authors declare that they have no competing interests.

\section{Author details}

'Department of Pediatric Dentistry, Faculty of Dentistry, Damascus University, Damascus, Syria. ${ }^{2}$ Centre for Measurement and Evaluation in Higher Education, Ministry of Higher Education, Damascus, Syria. ${ }^{3}$ Department of Psychiatry, Damascus University, Damascus, Syria. ${ }^{4}$ Department of Psychiatry, Almouwasat University Hospital, Damascus University, Damascus, Syria.

Received: 26 February 2019 Accepted: 25 December 2020

Published online: 10 February 2021

\section{References}

1. Freh F. Psychological effects of war and violence on children. J Psychol Abnorm. 2015;S1:1-2. https://doi.org/10.4172/jpab.S1-e001.

2. Burke S. Children and war: cycles of violence [Internet]. In psych. 2006 [cited 2015 Oct 7]. www.psychology.org.au/publications/Inpsych/2006/.
3. Latifeh Y, Dashash M. A critical analysis and a suggested reform of psychiatric curricula in medical faculties during Syrian crisis 2. The current psychiatric curriculum delivered in medical faculties in Syria that should be addressed in. Am J Health Res. 2012;2016(4):12-8.

4. Ballouk M, Dashash M. The gingival health status of 8-12 year old children in Damascus city in Syria during the Syrian Crisis: a cross-sectional epidemiological oral health survey. BMC Res Notes. 2018;11:887. https:// doi.org/10.1186/s13104-018-3998-x.

5. Rai B. Oral health in patients with mental illness. Internet J Dent Sci. 2007:6(1):1-4.

6. Mirza R, Phelan M, Wulff-Cochrane V. Oral health of psychiatric in-patients Psychiatr Bull. 2001;25:143-5.

7. Kisely S. No mental health without oral health. Can J Psychiatry. 2016;61(5):277-82.

8. Summerfield D. Conflict and health: War and mental health: a brief overview. BMJ. 2000;321:232-5.

9. Jordans MJD, Tol WA. Mental health and psychosocial support for children in areas of armed conflict: call for a systems approach. BJpsych Int. 2015;12(3):2009-12

10. Thabet A, Vostanis P, Karim K. Group crisis intervention for children during ongoing war conflict. Eur Child Adolesc Psychiatry. 2005;14:262-9.

11. Pynoos RS, Goenjian A, Tashjian M, Karakashian M, Manjikian A, Manoukian G, et al. Post-traumatic stress reactions in children after the 1988 Armenian earthquake. BJPsych. 1993;163:239-47.

12. Thabet A, Vostanis P. Post-traumatic stress reactions in children of war. J Child Psychol Psychiatry. 1999;40(3):385-91.

13. Jokovic A, Locker D, Stephens M, Kenny D, Tompson B, Guyatt G. Validity and reliability of a questionnaire for measuring child oral-health-related quality of life. J Dent Res. 2002;81(7):459-63.

14. Brown A, Al-Khayal Z. Validity and reliability of the Arabic translation of the child oral-health-related quality of life questionnaire (CPQ11-14) in Saudi Arabia. Int J Paediatr Dent. 2006;16(6):405-11.

15. Silness J, Löe H. Periodontal disease in pregnancy II. Correlation between oral hygiene and periodontal condition. Acta Odontol Scand. 1964;22(1):121-35.

16. Löe H, Silness J. Periodontal disease in pregnancy I. Prevalence and severity. Acta Odontol Scand. 1963;21(6):533-51.

17. WHO. Oral health surveys: basic methods. 5th ed. Geneva: World Health Organization; 2013. p. 1-137.

18. Schell-Faucon S. Developing education and youth-promotion measures with focus on peace-building and conflict-prevention. Eschborn; 2002.

19. Dybdahl R. Children and mothers in war: an outcome study of psychosocial intervention program. Child Dev. 2001;72:1214-30.

20. Al Bardaweel S, Dashash M. E-learning or educational leaflet: does it make a difference in oral health promotion? A clustered randomized trial. BMC Oral Health. 2018;18(81):1-8.

21. Tol W, Komproe I, Susanty D, Jordans M, Macy R, De Jong J. School-based mental health intervention for children affected by political violence in Indonesia: a cluster randomized trial. JAMA. 2008;300(6):655-62.

\section{Publisher's Note}

Springer Nature remains neutral with regard to jurisdictional claims in published maps and institutional affiliations.

Ready to submit your research? Choose BMC and benefit from

- fast, convenient online submission

- thorough peer review by experienced researchers in your field

- rapid publication on acceptance

- support for research data, including large and complex data types

- gold Open Access which fosters wider collaboration and increased citations

- maximum visibility for your research: over 100M website views per year

At BMC, research is always in progress.

Learn more biomedcentral.com/submissions 